\title{
Research on Path Selection of Logistics Enterprise Transformation and Upgrading
}

\author{
Chen Xiaochun \\ Business School, Beijing Wuzi University, Beijing, China
}

Email address:

327640307@qq.com, chenxiaochun_77@163.com

To cite this article:

Chen Xiaochun. Research on Path Selection of Logistics Enterprise Transformation and Upgrading. International Journal of Science, Technology and Society. Vol. 4, No. 5, 2016, pp. 67-73. doi: 10.11648/j.ijsts.20160405.11

Received: August 8, 2016; Accepted: August 15, 2016; Published: August 25, 2016

\begin{abstract}
In recent years, the growth of logistics enterprises is slowing down. On the one hand, it is the result of overall adjustment of the economic structure, on the other hand, it also shows that it is difficult to obtain sustainable development inon the current economic situation for logistics enterprises, all logistics enterprises are faced with a problem that how to transform and upgrade. This article aims at research on content of the logistics enterprise transformation and upgrading and the status of logistics enterprise development, this paper puts forward the basic path of the logistics enterprises transformation and upgrading.
\end{abstract}

Keywords: Logistics Enterprises, Basic Path, Transform and Upgrading

\section{Introduction}

\subsection{Accelerate the Merger and Reorganization of Enterprises to Integrate and Optimize the Resources and Management of Logistics}

In the Internet background, competition is more intense and environment is more changeable, which will accelerate the process of merger and reorganization of enterprises. The merger and reorganization form the synergy effect of technology, capital, management and other aspects, and improve the operation efficiency and scale efficiency of enterprises. At the same time, mergers are likely to change the competitive position of enterprises, improve market share, and grab a bigger market profit. The way of merger and reorganization verifies under the background of Internet, forced mergers and acquisitions gradually be reduced, and take a way of strategic alliance, stronger alliance, emphasizing complementary advantages and common development between enterprises.

If regard merger and reorganization of logistics enterprises as a dynamic process, then there needs a complete process from the beginning of merger and reorganization to the real integration, this requires to carry out a full range of integration to customer resources, information resources, operational processes, and logistics services capabilities.

It is always to further enhance the level of logistics business services after the completion of the resources integration, by the way of providing supply chain management services for customers. This has put forward the higher request to the logistics enterprise to improve ability of supply chain management service, and also the logistics enterprise have to construct its own network layout in the whole country and even the global node. Current practice is mainly aimed at the upstream enterprises to provide international freight forwarding, transportation and distribution, VMI warehousing, supply chain finance and other services. With the rapid development of the Internet, especially for the downstream customers, companies directly provide more personalized, customized services will be a new profit growth point for the future company. STO and daily express announced a major strategic of restructuring. The strategic restructuring will fully integrate enterprise resource in products, operations, information technology, express the last 1 $\mathrm{km}$ field, thus speeding up the construction of the service level of logistics enterprises, and enhance the service ability of logistics enterprise. STO, who is providing traditional courier service, at the same time actively expand the new business to provide third party logistics and warehousing, logistics and distribution, valuables channel for the large domestic C2C, B2C enterprises etc.

\subsection{Build the Internet Logistics Platform to Layout Physical Network}

Informatization level is an important index that can reflect and determine the efficiency of logistics operation. Information 
asymmetry will get great improvement in both supply and demand, the information difference between the two will become more and more small, and the information is more and more transparent; through the construction of information platform, more resources can be fully utilized and get more accurate information and data in actual operation; so logistics information system cannot be ignored. For building logistics platform, the first step is sorting out the purpose and ideas of building. According to the nature of logistics platform, it can be divided into management platform and physical platform, according to the function, it can be divided into comprehensive platform and professional platform, only clearly thinking firstly can we confirm the goal of building a platform. Second, analysis on the platform function needs, including the platform of the enterprise, consumers and related regulatory requirements. Third, build a logistics platform achieve modular, the core module includes transport module, storage and distribution module, each module independently be designed through the integration of information technology.

From the point of view of 2015 National Bureau of statistics released the latest survey data, the growth rate of e-commerce remained at a double-digit, in 2014, the whole society e-commerce transactions has reached unprecedented 16.39 trillion, achieved an increase of $59.4 \%$. Form the specific point of view, in the pure proprietary platform to achieve the transaction amount and the growth rate has reached the highest level, followed by the pure third party platform and mixed business platform. The ecological model of Alibaba provides a very valuable reference for us, it based on the perspective of the platform, and gradually extends to the value of data, flow, marketing, financial and other, ultimately achieve a win-win situation with customers. All in all, the platform should be highly opened to promote the coordinated development of various organizations.

Firstly, Collaborative development is necessary between logistics platform and the integration of the physical network, only in this way the logistics enterprises be will a highly competitive enterprise for development. Sensor technology, electronic data exchange technology, bar code technology, radio frequency identification technology, safety and security, which are the guarantee to realize the information sharing and information communication online platform and under line network; secondly, information should be coordinated. Logistics information is very large, and the timeliness of the information and the accuracy of the requirements are very high, information collaboration to ensure meet the customer need in a timely and accurate manner. Thirdly, Management should be coordinated, management collaboration will ensure the normal operation of each subsystem and the physical network, and effectively put those two together.

\subsection{Carry out Cross-Border Operations to Extent the Industrial Chain}

Under the environment of Internet, logistics enterprises are more and more closely cooperated with the traditional manufacturing enterprises. With the development of electronic commerce, logistics enterprise also gradually extending to the first industry that the agriculture, and other third industry such as retail industry, such as SF, who is taking original direct mining model of preferring for fresh food, Therefore, the development of electricity suppliers is said to be the direct cause of logistics enterprises to carry out cross-border operations. But the development of cross-border operations should pay attention to the following points: (1) the need to invest a lot of money in cross-border operations, it is difficult to attract the attention of venture capital for the lack of funds and profit meager logistics enterprises. (2) Cross border operation itself is a kind of diversified development. Logistics enterprise is still relatively lack of operation experience for the unfamiliar field. Need to combine their advantages with cross-border operations. (3) Trans boundary operation requires advanced technical support, logistics enterprises requires a high level of information technology.

Change the business model under the condition of Internet can help the logistics enterprises to develop the international market. There are many private courier companies through cooperation with foreign airlines access to certain international line. The traditional international logistics that the manufacturing and trade areas need to support the Internet platform. On the one hand, to reduce the risk and transaction costs of international logistics transactions; on the other hand, it also contributes to enterprise trading experience more smoothly in the field, and truly become a complete industry ecosystem. For example: Su Ning overseas purchase business has covered Japan, the United States and other countries and regions, and has built 53 stores and independent stores. It is understood that Su Ning has opened the United States, Japan, China Hongkong three international logistics routes, the future will be the layout of the United States, Japan, South Korea, China Hongkong overseas positions. Su Ning is accelerating the 7 cross-border pilot cities in the bonded warehouse construction, planning convergence with domestic logistics network. Import retail market penetration and market size will continue to rise in the next few years, cross-border logistics will become one of the important strategies for the future development of logistics enterprises.

\section{Evaluation Index System of Logistics Enterprise Path Selection}

\subsection{Determinate the Index System of Logistics Entzerprise Path Selection}

About the influencing factors of choosing the path of logistics enterprise transformation and upgrading, there are few specialized studies for this problem in the literature, but logistics enterprise transformation and upgrading is the fundamental change of the enterprises, and also relates to the sustainable development of enterprises. According to the theory of enterprise resources and capacity, the transformation and upgrading of logistics enterprises is a strategic decision made by enterprises with special resource collection in a certain sense. In this paper, determine the path selection index elements belongs to the strategic and directional research, so 
in order to clear the research, this paper only lists the key factors that affect the path selection of logistics enterprise transformation and upgrading.

\subsubsection{Corporate Entrepreneurship}

Researchers generally believe that corporate entrepreneurship can effectively anticipating changes in the market, and make the best use of the circumstances to reasonable arrange enterprise organization, which can help the enterprises obtain the competitive advantage. Specialized believed that entrepreneurship is mainly reflected in the spirit of innovation and can effectively bear and resolve the uncertainty in the development process of enterprises.

Logistics enterprise transformation and upgrading face all aspects of the problem, which is the product under the joint action of internal and external factors, it is due to the complexity and uncertainty of the transformation, entrepreneurs need certain spirit of innovation and adventure, so entrepreneurship can be regarded as an important factor affectting the path of logistics enterprise transformation and upgrading.

Enterprise is a collection of various resources, the differences between enterprises is the main source to the differences resources owned by the enterprise, the enterprise organizational capability, resources and knowledge accumulation of corporate profits and keep competitive advantage are of great significance. Logistics enterprises have the key resources that play a decisive role on how to carry out the transformation and upgrading of logistics enterprises and what is the direction to transformation and upgrading.

\subsubsection{Capital}

Capital is the blood of enterprises, the development of any enterprise cannot be separated from the support of funds. As a producer service industry, logistics enterprises need a lot of financial support to construct infrastructure, introduce advanced equipment and the use of information technology. Enterprises need to obtain competitive advantage and to promote the further development by the transformation and upgrading.

Talent is a very scarce resource for the development of enterprises. Any innovation or creation comes from people, so the talent factor is one of the key factors of logistics enterprises transformation and upgrading. Human resources cannot imitate mainly influenced by the enterprise's unique culture, history and social complex, so this is the difference between the enterprises and competitors, becoming an effective tool of the competition strength.

\subsubsection{Factor of Scale}

The majority of empirical studies have confirmed that enterprise size is an important factor to the transformation and upgrading of enterprises, and they are linear or nonlinear relationship. It will also affect the choice of logistics enterprise path. For enterprise scale, generally evaluate from several aspects of the registered capital, income, plant area and the number of employees.

To a certain extent, registered capital is a legal concept that reflects the size of enterprise.

Income is the economic benefits of the enterprise's daily business activities; it can be seen through operating income increase or decrease the size of the enterprise.

Storage area refers to the area of logistics enterprise warehouse, distribution center, etc. the size of the area will affect the ability of logistics enterprises to provide services, and will also affect the path selection of enterprises transformation and upgrading.

Employee number refers to the number of employees in the enterprise. It is also important to enterprises transformation and upgrading.

\subsubsection{The Factor of Enterprise Capability}

Customer put forward higher requirements on enterprise ability under Internet. This mainly refers to the service ability of logistics enterprises and the level of technical. The continuous improvement of service will improve the service ability of enterprises and promote carry on the path choice of logistics enterprise.

The service ability of logistics enterprises includes the basic service ability and the value added service ability and so on. With the continuous development of the Internet, customers put forward higher requirements for value-added service ability of logistics enterprises, more requirements of logistics enterprises can in accordance with customer demand for the goods on time and safety reach the hands of customers in the exact place. The difference of service ability of logistics enterprises will make the logistics enterprises choose different paths of transformation and upgrading.

Technical level can reflect the degree of information of logistics enterprises. Higher technical level is conducive to the construction of information and to promote the logistics business to build a logistics platform, along the path of collaborative development of the online and offline to achieve the transformation and upgrading.

\subsubsection{Environmental Factors}

Environment has a significant impact on the transformation and upgrading of logistics enterprises. Branch of the management and the government intervention the logistics enterprises are not conducive to the transformation and upgrading of logistics enterprises and development. Environmental factors mainly include two aspects of the market demand and competitive environment.

To meet the needs of the market is the primary value of the enterprise, the transformation and upgrading of logistics enterprises will be the first step to promote the market demand. Therefore, the logistics enterprises cannot carry out the transformation and upgrading if without the analysis of the market demand. Market demand not only includes the current demand, but also includes the potential demand; enterprises to successfully transform must build on the basis of market demand. At the same time, with the deepening of globalization and the increasingly fierce international competition, the transformation and upgrading of logistics enterprises are bound to take the factors of international competition into account.

\subsection{Determine the Weight of Evaluation Index System}

According to the above analysis and the evaluating method, 
can get the weight of each index as following table 1 .

Table 1. The weight of each index.

\begin{tabular}{|c|c|c|c|c|c|c|c|}
\hline indicators & sub-indicators & $\begin{array}{l}\text { The first } \\
\text { path index } \\
\text { weight }\end{array}$ & $\begin{array}{l}\text { The second } \\
\text { path index } \\
\text { weight }\end{array}$ & $\begin{array}{l}\text { The third } \\
\text { path index } \\
\text { weight }\end{array}$ & $\begin{array}{l}\text { The first path } \\
\text { sub index } \\
\text { weight }\end{array}$ & $\begin{array}{l}\text { The second } \\
\text { path sub index } \\
\text { weights }\end{array}$ & $\begin{array}{l}\text { The third path } \\
\text { sub index } \\
\text { weights }\end{array}$ \\
\hline \multirow{2}{*}{$\begin{array}{l}\text { entrepreneurship } \\
\text { (x1) }\end{array}$} & creative spirit & \multirow{2}{*}{0.10} & \multirow{2}{*}{0.13} & \multirow{2}{*}{0.15} & 0.07 & 0.09 & 0.08 \\
\hline & adventurous & & & & 0.03 & 0.04 & 0.07 \\
\hline \multirow{4}{*}{$\begin{array}{l}\text { Enterprise } \\
\text { Resources (x2) }\end{array}$} & Human resources & \multirow{4}{*}{0.35} & \multirow{4}{*}{0.25} & \multirow{4}{*}{0.28} & 0.09 & 0.06 & 0.06 \\
\hline & Capital resources & & & & 0.11 & 0.07 & 0.10 \\
\hline & Logistics facilities and equipment & & & & 0.07 & 0.06 & 0.03 \\
\hline & Brand resources & & & & 0.08 & 0.06 & 0.09 \\
\hline \multirow{4}{*}{$\begin{array}{l}\text { Enterprise scale } \\
\text { (x3) }\end{array}$} & registered capital & \multirow{4}{*}{0.23} & \multirow{4}{*}{0.16} & \multirow{4}{*}{0.14} & 0.05 & 0.03 & 0.03 \\
\hline & Business income & & & & 0.09 & 0.06 & 0.06 \\
\hline & warehouse & & & & 0.06 & 0.06 & 0.03 \\
\hline & Number of employees & & & & 0.03 & 0.01 & 0.02 \\
\hline \multirow{2}{*}{$\begin{array}{l}\text { Enterprise } \\
\text { capability (x4) }\end{array}$} & Service capability & \multirow{2}{*}{0.12} & \multirow{2}{*}{0.25} & \multirow{2}{*}{0.20} & 0.08 & 0.10 & 0.12 \\
\hline & technical level & & & & 0.04 & 0.15 & 0.08 \\
\hline \multirow{2}{*}{$\begin{array}{l}\text { environmental } \\
\text { elements (x5) }\end{array}$} & market demand & \multirow{2}{*}{0.20} & \multirow{2}{*}{0.21} & \multirow{2}{*}{0.23} & 0.08 & 0.14 & 0.12 \\
\hline & Competitive environment & & & & 0.12 & 0.07 & 0.11 \\
\hline Total & & 1 & 1 & 1 & 1 & 1 & 1 \\
\hline
\end{tabular}

\section{The Path Selection of Logistics Enterprise Transformation and Upgrading}

According to the overall goal of the logistics enterprises transformation and upgrading, logistics enterprise must consider these factors: elements of entrepreneurship, enterprise resources, enterprise scale factors, enterprise capability elements, and environmental factors. In this paper, use the following theoretical model to illustrate the general path of the logistics enterprises transformation and upgrading.

$\mathrm{Z}$ stands for the objective function, refers to the logistics enterprises from traditional logistics enterprise into modern logistics enterprises by transformation and upgrading. X1 represents the spirit of entrepreneurs, $\mathrm{X} 2$ represents resource variables, refer to the key resources; X3 represents scale variables, refers to the scale of enterprises; X4 represents capability variables; X5 represents environment variable, refers to the external market demand and competition; $t$ represents the time variable. The path is set in three stages of the logistics enterprise transformation and upgrading, each stage will be affected by the different levels of the 4 variables. The trend of enterprises in the three stages as following:

1. at time $\mathrm{t}=\mathrm{T} 1-\mathrm{T} 0$, variable $\mathrm{x} 1, \ldots, \mathrm{X} 5$ play a role in the enterprise, the trend of enterprise from $\mathrm{Z} 0$ to $\mathrm{Z1}$;

2. at time $\mathrm{T} 2-\mathrm{T} 1$, variable $\mathrm{X} 1, \ldots, \mathrm{X} 5$ play a role in the enterprise, the trend of enterprise from $\mathrm{Z} 1$ to $\mathrm{Z} 2$;

3 . at time $\mathrm{t}=\mathrm{T} 3-\mathrm{T} 2$, variable $\mathrm{x} 1, \ldots, \mathrm{X} 5$ play a role in the enterprise, the trend of enterprise from $\mathrm{Z} 2$ to $\mathrm{Z} 3$;

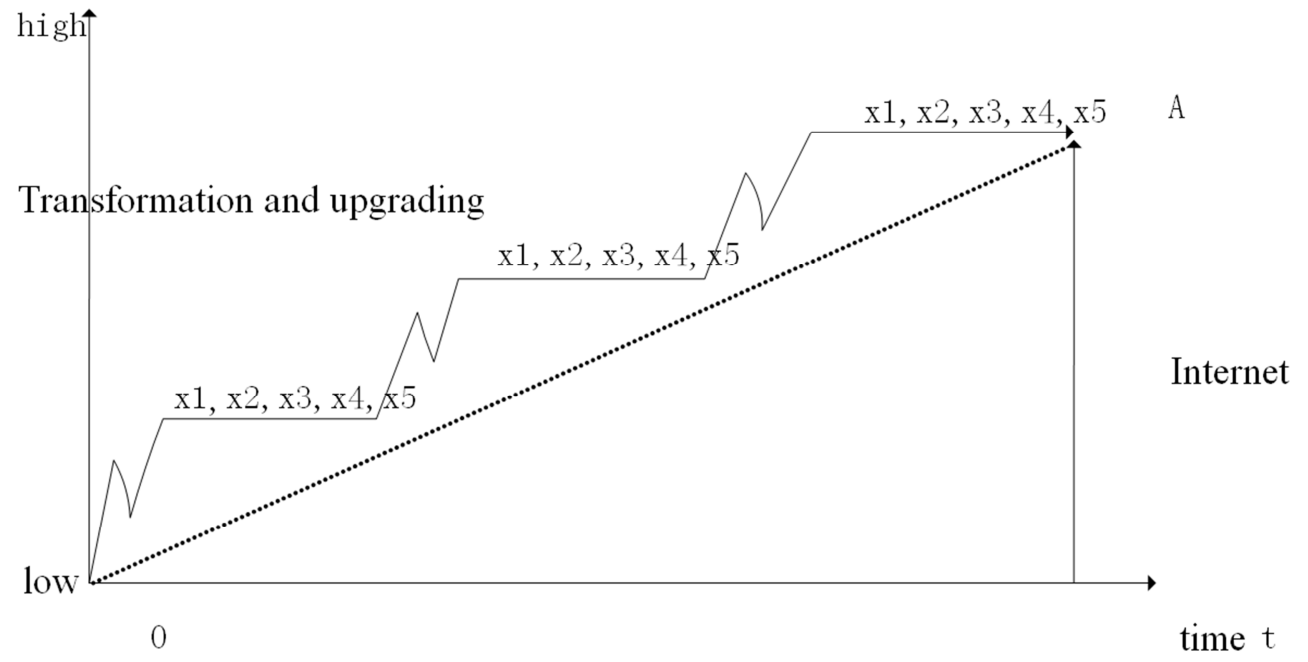

Figure 1. General path theory model of logistics enterprise transformation and upgrading 
Assuming that $\mathrm{x} 1, \mathrm{X} 2, \mathrm{X} 3, \mathrm{x} 4, \mathrm{X} 5$ all play a role, then the path of the enterprise is a continuous process of change.

From the above figure can be known, the starting point is 0 , and ultimately reach to the end point $\mathrm{A}$, basically experienced three major stages in the process of logistics enterprises carry out transformation and upgrading. In the Internet environment, each stage is affected by five factors, three stages are not completely smooth continuous curve, but there are some fluctuations reflect the risk of the process of transformation and upgrading. But in every stage, the enterprise is a step forward, the overall competitiveness of enterprises will be enhanced. The logistics enterprises can achieve the purpose of transformation and upgrading through these three stages. This process is an abstract process of the continuous cycle, if enterprises want to achieve sustainable development then enterprises need to continually look for a breakthrough, every moment in change.

According to the above analysis and the results of the previous research, combined with the relevant theory and literature of the logistics enterprise transformation and upgrading, the following is a specific analysis of the path selection:

Overall, resources is lager affected by path selection of enterprise logistics transformation upgrade, the first path lager affected by scale factor, with related to carry out mergers and acquisitions of logistics enterprises, the second path is greater affected by enterprise capability elements; the third path affected by enterprise resource, and it is inseparable from the stimulus of environmental elements.

\subsection{The First Path Selection of Logistics Enterprise Transformation and Upgrading}

Specifically, when the logistics enterprise is rich in resources, the smaller scale of the enterprise and the competition increasingly intense, entrepreneurs tend to accelerate the merger and reorganization of enterprises, integrate and optimize the logistics resources and management, provide the path of integration supply chain management services. As shown in the following figure 2 . When there is smaller scale of logistics enterprise, there will be the size of the economy. The merger and reorganization of logistics enterprises need to change different organizations, so the human factors are very important. Leaders of the entrepreneurial can eliminate the obstacles in the merger and reorganization, and also will directly affect the effect of change.

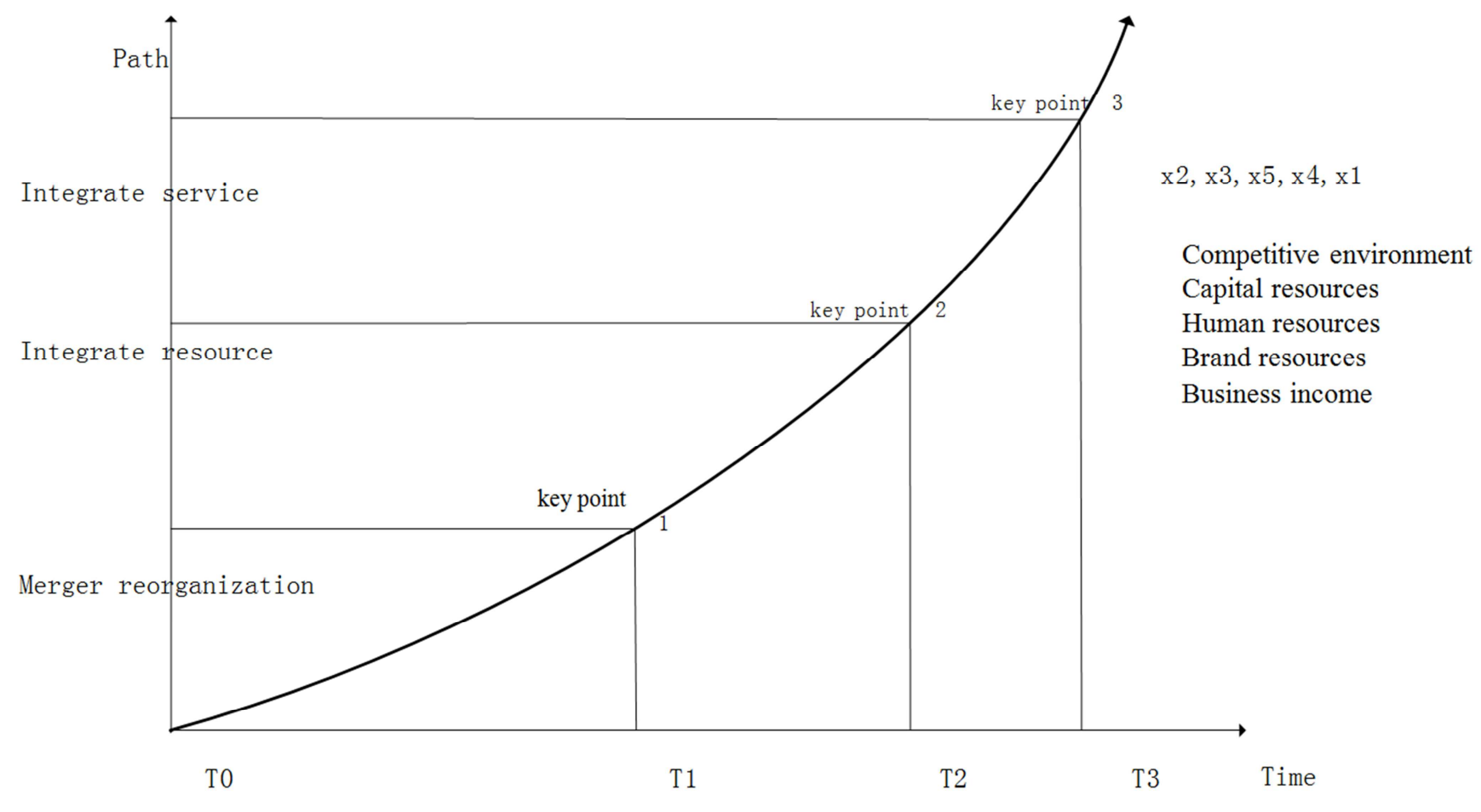

Figure 2. The first path of logistics enterprise transformation and upgrading.

\subsection{The Second Path Selection of Logistics Enterprise Transformation and Upgrading}

When the technical level of enterprise logistics is high, resources are abundant and entrepreneurs have the spirit of innovation, the tendency to choose to build the path of Internet logistics platform, the layout of the physical network to promote the development of online and offline cooperative. As shown in the following figure 3 :

First, it is necessary to construct the logistics platform, combining the information flow with logistics closely together in the virtual world, the technical level effect is larger for the path selection of logistics enterprise transformation and upgrading in key point 1; then to layout physical network, logistics is flow of entities, everything is empty if enterprises cannot construct physical network. Last, combining tangible with intangible net together to promote coordinated development of online and offline, market demand and service ability to have greater impact for enterprises. 


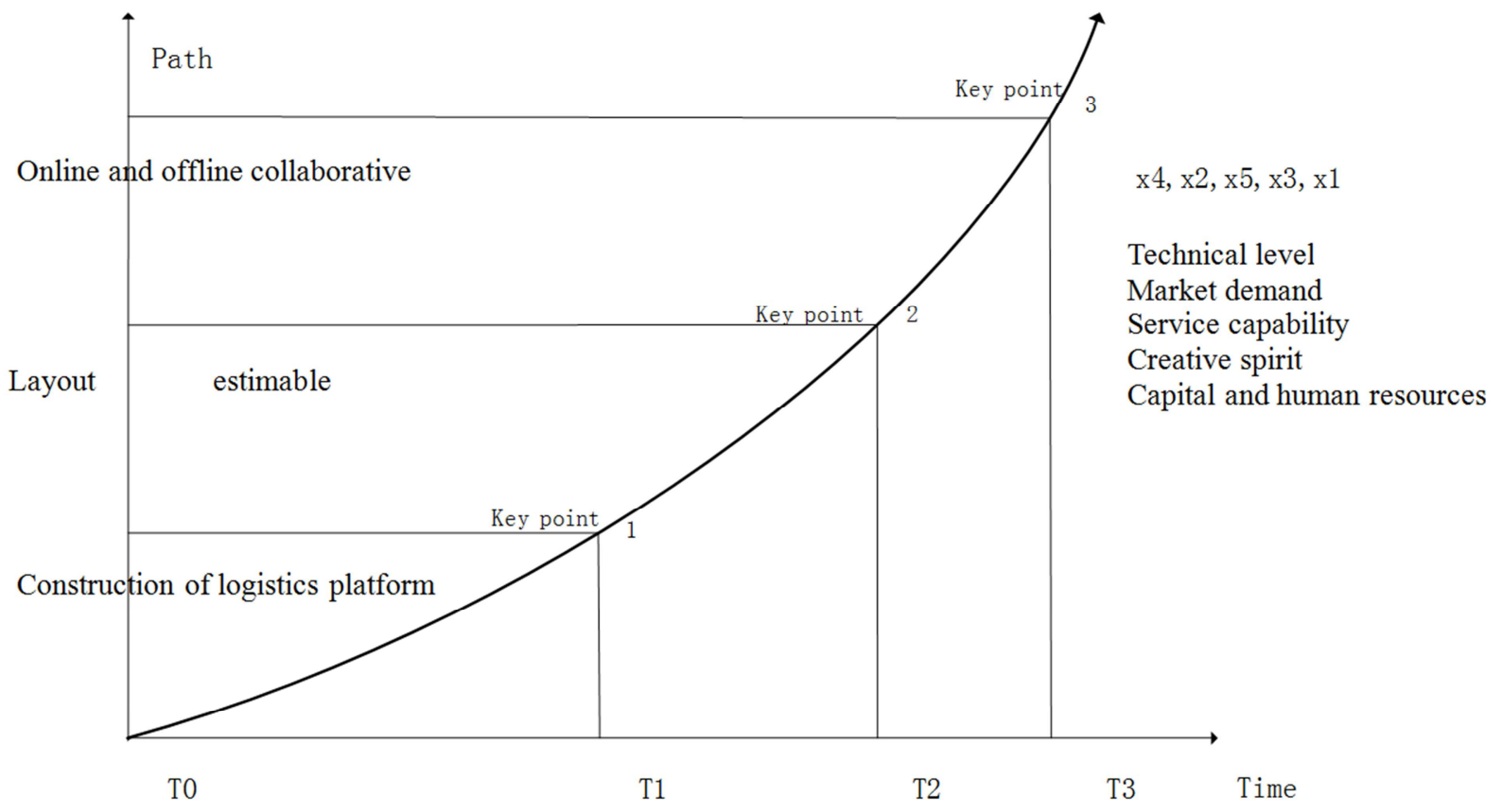

Figure 3. The second path of logistics enterprise transformation and upgrading.

\subsection{The Third Path Selection of Logistics Enterprise Transformation and Upgrading}

When there is huge market demand for the logistics enterprise, the competitive environment is becoming more intense, the entrepreneur tends to choose the path of carrying out cross-border operations, extend the industrial chain to open up international market. As shown in the following figure 4:

With the development of the Internet, logistics enterprise boundary is more and more increasingly blurred, first to identify the borders of their own, logistics can use their own operation ability to carry out cross-border; next to the expansion of the scope of business, extending industrial chain, create more profit; and enhance the innovation ability to improve the level of logistics services and explore the international market, take participate in international competition. The requirements for the service ability is also high and need to continuous improvement service ability for logistics enterprise in the choice of the path; at the same time it is necessary to analysis the market demand to create a good international competition policy environment and legal environment, and also contribute to cross-border business.

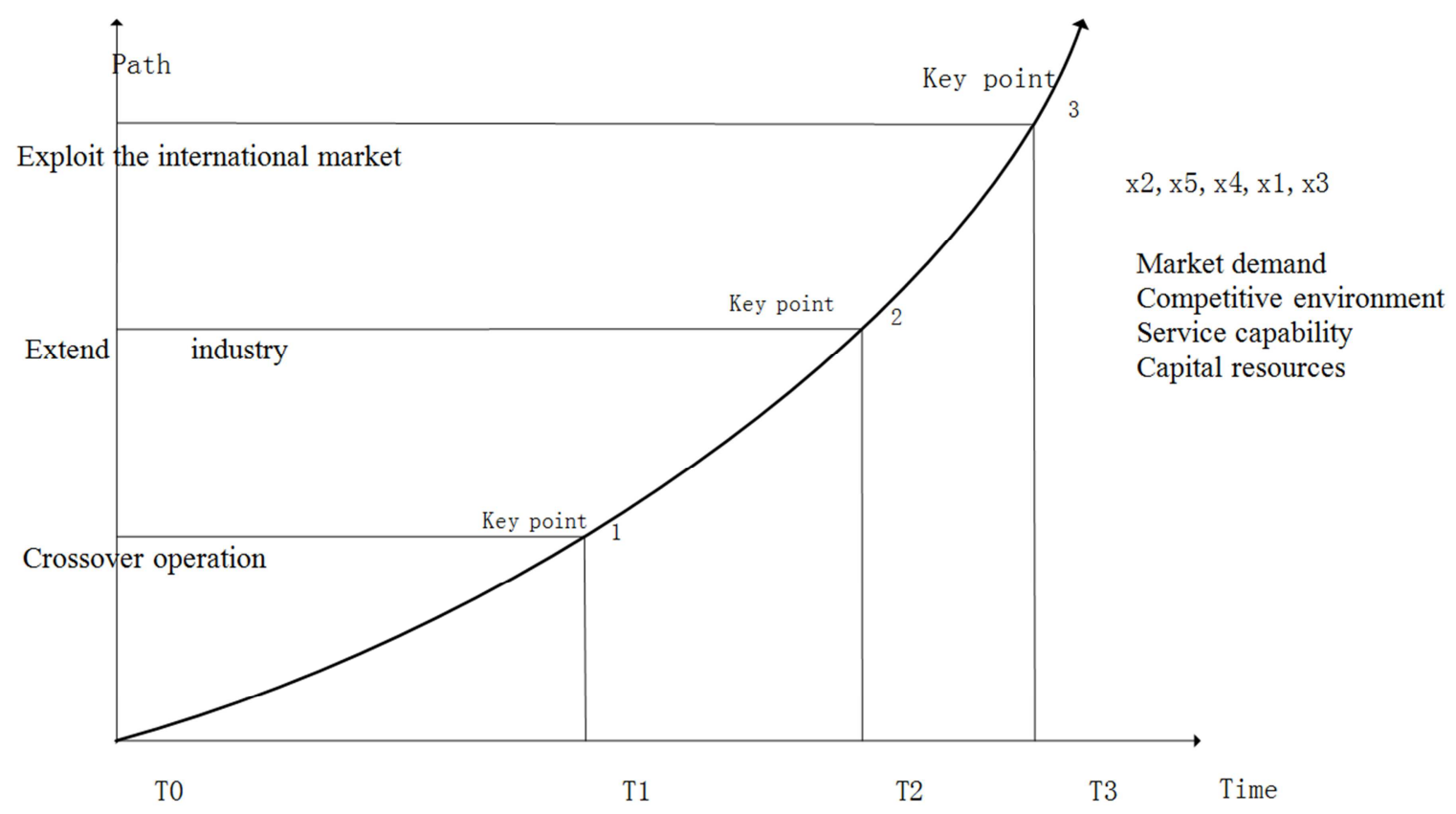

Figure 4. The third path of logistics enterprise transformation and upgrading. 
There may be several paths at the same time in path selection of enterprises, in order to adapt to the current conditions Internet the rapid change of market demand. It is entirely possible to achieve the condition of Logistics enterprises have very rich resources an innovative ability, scale reach to a certain extent, and has a favorable external develop environment.

\section{Conclusion}

This paper analyzes the ideas and influence factors of logistics enterprise transformation and upgrade, and then put forward the model and the general path of logistics enterprise transformation and upgrade, there are mainly three paths, then according to the influencing factors to determine the main evaluation indicators of the logistics enterprises path choice, in this paper using expert scoring method to determine the influencing factors weights of each path, so as to help the logistics enterprises to upgrade path. Hope the paper can provide guidance and reference for logistics enterprises.

\section{References}

[1] Mao Yunshi, Wu Yao. Research on the paths and patterns of enterprises upgrading [J]. Zhongshan University, 2009, 49 (1).

[2] Li Huashen, Wu Jiaxi. An investigation report on the small and medium enterprises transformation and upgrading in Zhejiang province [J]. Management world, 2009 (08).
[3] Dai Zhiwei, Xuan Guoliang. Study on the transformation strategic of large foreign trade enterprises based on the value chain reorientation [J]. Journal of East China Normal University, 2011 (4).

[4] Yang Yi Qiong. Motivation analysis and Path Research on enterprises transformation and upgrading $[\mathrm{J}]$. Development and research, 2012 (6).

[5] Liu Bin. Study on the path of enterprise transformation and upgrading in post financial crisis [J]. Financial and economic circles (Academic Edition), 2011 (9).

[6] Wang Zuo. On the transformation and upgrading of logistics enterprises [J]. China's circulation economy, 2014 (2).

[7] Collar Wang, Martha, Wang Lingyu. Research on the model of logistics enterprise transformation [J]. Logistics engineering and management upgrading, 2014 (5).

[8] Yang Yang. Research on the upgrading and formation of logistics enterprises based on networking [J]. Logistics technology, 2013 (3).

[9] Yang Sidong. Study on the path selection of small and medium enterprises transformation and upgrading J]. Commercial economy, 2012 (21).

[10] Han Jichao. Study on the path of traditional manufacturing enterprises transformation and upgrading based on value Galaxy [J]. Enterprise management, 2014 (9).

[11] $\mathrm{Wu}$ Xiukui. The problems on traditional logistics enterprise transformation and upgrading in the process of operation management [J]. Logistics technology, 2015 (7). 